\title{
Units of information on dynamic message signs: a speed pattern analysis
}

\author{
Snehanshu Banerjee, Mansoureh Jeihani", Nashid K. Khadem and Danny D. Brown
}

\begin{abstract}
A single unit of information is an answer to any anticipated question a motorist may ask. Such questions include: "What happened? Where? What do I do?" This study, a first of its kind, analyzes the optimum number of units of information Dynamic Message Signs (DMSs) should display to influence driver speeding behavior. A $155-$ mi $^{2}$ virtual road network of the Baltimore-Washington Parkway (MD-295) in Maryland was developed for use with a mediumfidelity driving simulator, and 65 participants took part in the study. Six scenarios featured DMSs displaying 2-7 units of information, interchangeably, and a total of 296 simulation sessions were conducted. Mean speeds are calculated over five different phases: the initial speed area, visible area, readable area, lost legibility area and post DMS area. Analysis of variance (ANOVA) and post-hoc analysis showed that participants tend to accelerate as soon as they lose sight of the DMS displaying 2-3 units of information and continue to do so after they pass the DMS. An ordinary least squares (OLS) regression analysis reveals that participants older than 55 slow down the most when they encounter DMSs with 6-7 units of information. Participants in the age group of 26-35 tend to increase speeds, especially when a DMS displays 2-4 units of information. This suggests that the comprehension time is low when there are fewer units of information on a DMS. Too little information may be unclear or ambiguous whereas too much may be hard to comprehend and cause drivers to slow down.
\end{abstract}

Keywords: Driver behavior, Driving simulator, Speed study, Dynamic message signs, Units of information

\section{Introduction}

In contemporary times, Dynamic Message Signs (DMSs) also called Variable Message Signs (VMSs) are a common sight on highways. Transportation agencies in different states use these signs to display traffic-related information involving current traffic conditions, work zone hazards, travel time and incidents, among others. DMSs improve freeway operations, are efficient and assist in traffic control [1,2]. State highway authorities consider DMS an effective tool for communicating with drivers [3]. As an integral part of advanced transportation systems, DMSs also help drivers make quick travel decisions and improve mobility and safety. Numerous works of research have been carried out studying distracted driving patterns involving DMSs and their impact on speed variation [1-11]. Drivers may need to give more attention and time to read the DMS [12-15], which is why drivers sometimes slow down near a DMS,

\footnotetext{
* Correspondence: mansoureh.jeihani@morgan.edu

Department of Transportation and Urban Infrastructure Studies, Morgan State University, 1700 E. Cold Spring Lane, Baltimore, MD 21251, USA
}

affecting traffic flow [16]. One such study based on a survey revealed that $90 \%$ of the drivers would at least sometimes slow down when approaching an active DMS [10]. Another study, that was based on radar readings near a DMS, found that drivers tend to slowdown as they approach a DMS, with radars that are placed nearer to the DMS recording more reduction in speed [17]. Furthermore, a DMS might cause an unintentional increase in travel speed, as was observed by Chatterjee et al. [18]. In this study, through field trials in London and Turin, it was observed that a DMS, with an immediate incident warning sign, results in an increase in the travel speed by around $3 \%$, on average, as drivers wanted to balance the anticipated delays. Thus, researchers are looking into the content of a DMS so that the expected advantages of a DMS do not turn into disadvantages like slowdowns, delays or even crashes [12-14]. Standard guidelines define "message load" as the units of information in the entire message, a measure of the amount of total information displayed in a message $[19,20]$. One unit of information can be described as an answer to a 


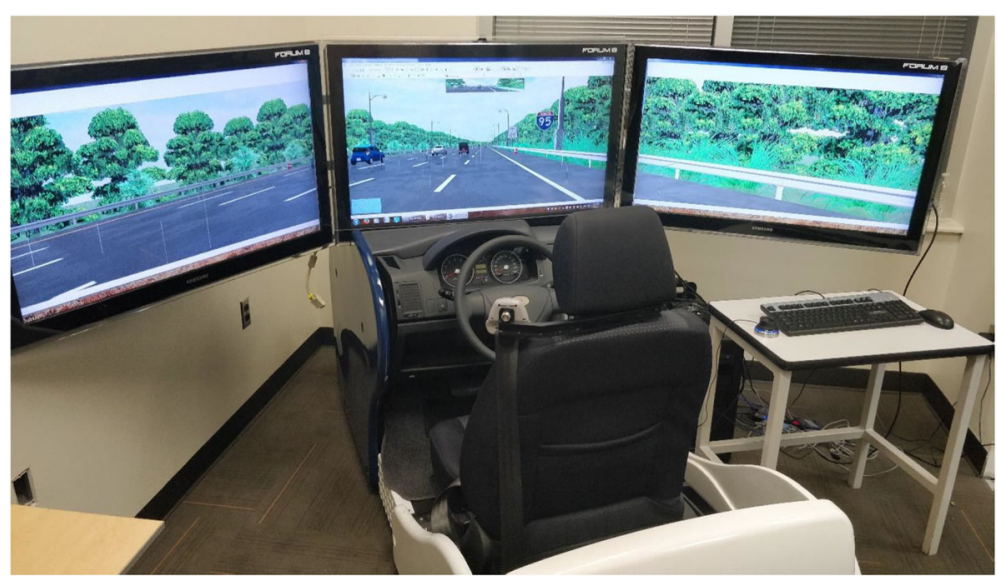

Fig. 1 Driving Simulator at the SABA Center, Morgan State University

query a motorist might have or a piece of data that they can recall and utilize to make a decision. For example, the following anticipated queries involve six units of information: "Where? (STADIUM), how long? (30 MIN), which route? (VIA US-1), how long? (20 MIN), which route? (VIA MD-295), how long? (15 MIN)." Each unit of information is usually one or two words and typically less than five words, as the average motorist cannot comprehend more than one unit of information each second $[19,20]$. The authors found several studies stating the importance of length of messages on a DMS but were unable to find studies focusing on the importance

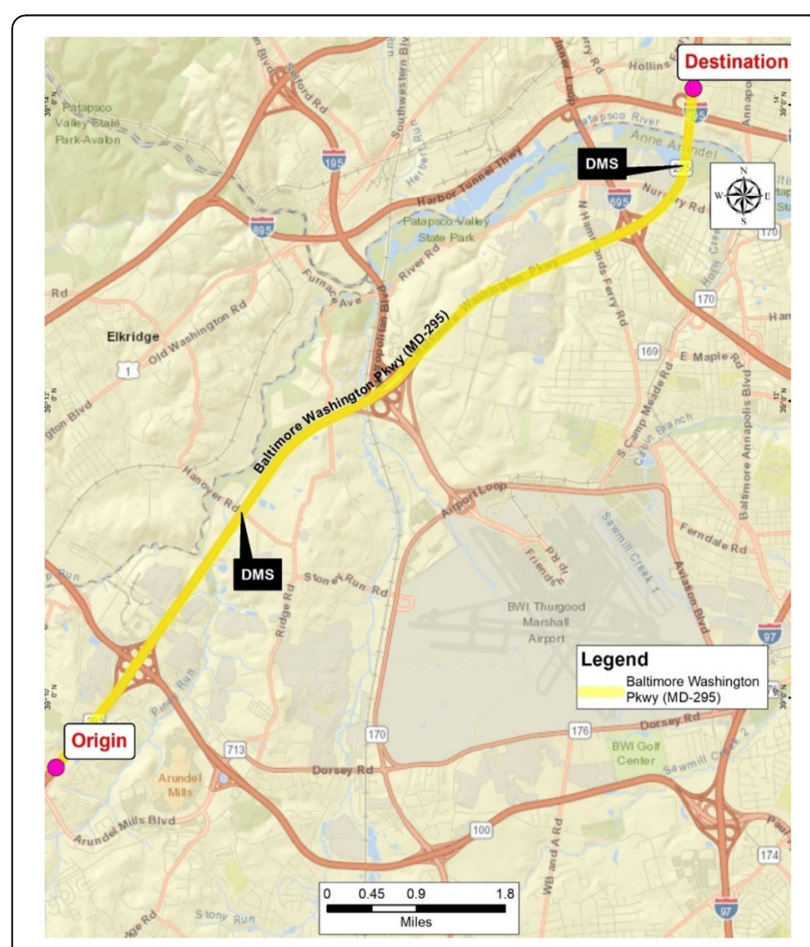

Fig. 2 The Study Corridor of DMSs based on units of information. This study, in a first of its kind, investigates the influence of units of information on a DMS display on driver speeding behavior. Nowadays, researchers have been using the evolving driving simulator (DS) technology to investigate driver behavior under various conditions $[4,6,8,10,11,21-$ 27] and as such, this study uses a medium-fidelity driving simulator to conduct this speed study.

The influence of DMSs on driver behavior depends on different factors, which include low visibility, weather conditions, age, and length of the message and display time $[4,10,28-31]$. In some cases, after reading the DMS, motorists increased their speed upon passing the DMS to account for speed loss during the slowdown [9]. Some studies show that drivers older than 35 have a higher possibility of speed reduction while encountering a DMS [4]. A driver's ability to read and understand a message can vary significantly based on age, and older drivers need more time to read as well as understand the information on a DMS [5]. Some studies argue that older drivers are more experienced while younger drivers tend to be easily distracted, but younger drivers have quicker processing and reaction times and are more familiar with technology [4]. Studies also show that drivers with higher education levels read and try to follow the DMS [4] compared to drivers for whom English is not their first language or drivers who are less educated [3]. Another study suggested that female drivers are less likely to follow the DMS; while business travelers tend to adhere to a DMS more than regular commuters [32]. Analytical results show that the average speed changing behavior is 2 to $25 \mathrm{~km} / \mathrm{h}$ in the presence of VMSs compared to locations without VMSs [6]. These results also show that there is a reduction in speed ranging from 11 to $15 \mathrm{~km} / \mathrm{h}$ before, at and after VMS locations compared to locations without VMSs [6]. 


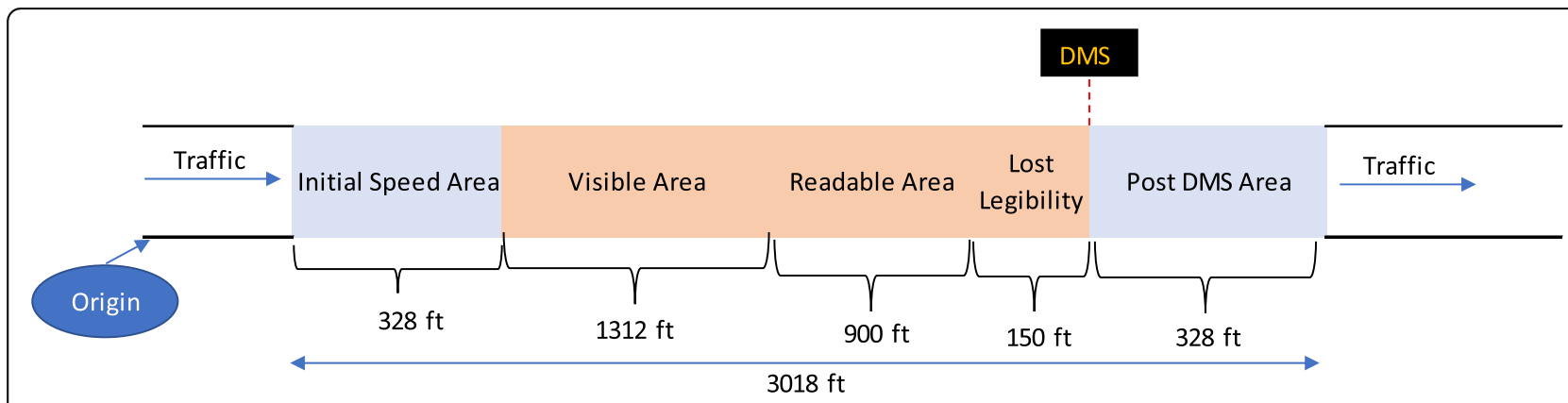

Fig. 3 Work zone signs tested in this study (The dimensions are not to scale)

A study by Haghani et al. [7] shows that driver speeding behavior is also influenced by the type of message. Drivers slowed down the most when encountering warning messages. Comparatively, they did not slow down as much when encountering regulatory messages and non-traffic related messages. DMSs displaying messages like "Prepare to Stop" and "Stopped Traffic Ahead" resulted in a maximum decrease in speeds [8]. A drivers' survey showed that messages displaying speed limits and work zone incidents were preferred and participants were more likely to follow them. The results from the drivers' survey reinforced the fact that these signs were effective in reducing vehicular speeds [8]. Moreover, a study in Finland using traffic monitoring stations found that a "slippery road" sign led to a speed reduction of $1.2 \mathrm{~km} / \mathrm{hr}$. and $2.1 \mathrm{~km} / \mathrm{hr}$. when the sign was flashing; while a "minimum headway" sign led to only a $1 \mathrm{~km} / \mathrm{hr}$. reduction in speed [33].

The size of messages or repetition also influences driver behavior. Some DMSs display messages in more than one phase with lots of information which also causes a slowdown $[10,29]$. Though the repetition of messages has no significant effect on speed or route

Table 1 Units of Information used for analysis

\begin{tabular}{|c|c|c|}
\hline $\begin{array}{l}\text { Information } \\
\text { on DMS }\end{array}$ & $\mathrm{Me}$ & iges \\
\hline 2-3 units & $10 \mathrm{MI} 25 \mathrm{MN}$ & $\begin{array}{l}\text { ROADWOFK AHEAD } \\
\qquad 1 \text { II } \\
\text { LEFT LN CLOSED }\end{array}$ \\
\hline 4 units & $\begin{array}{l}\text { ROADNORK PAST I- } 195 \\
\text { LEFT LN CLOSED } \\
\text { KEEP RIGHT }\end{array}$ & $\begin{array}{l}\text { CRASH } \\
\text { 1-95 PAST |- } 195 \\
\text { STAY ON ND- } 295\end{array}$ \\
\hline 5 units & $\begin{array}{l}\text { CAASH I-95 PAST |- } 195 \\
\text { STAY ON MD-295 } \\
\text { SAVE } 10 \mathrm{MIN}\end{array}$ & $\begin{array}{c}\text { CRASH I-95 PAST l195 } \\
15 \text { MN LELAY } \\
\text { STAY ON ND } 295\end{array}$ \\
\hline 6-7 units & $\begin{array}{l}\text { STADIUM } 28 \text { MN } \\
\text { VIA US- } 1 \quad 15 \text { MN } \\
\text { VIA MD-295 } 12 \quad \text { MIN }\end{array}$ & $\begin{array}{l}10 \text { MI VIA US- } 125 \text { MIN } \\
\text { VIA } 1-95 \quad 30 \text { MN } \\
\text { VIA MD- } 295 \quad 20 \text { MN }\end{array}$ \\
\hline
\end{tabular}

choice [28], the display time is an essential factor to allow drivers to read the DMS. Sometimes traffic delays can be a result of a chain reaction of vehicles slowing down due to a DMS [11]. The placement of the DMS sign also affects driver's behavior. Though some studies did not find any relation between speed reduction and traffic congestion due to DMS, only $17 \%$ of cases resulted in speed reduction while in $83 \%$ cases, there was an increase in vehicle speed or no change at all [7].

\section{Methodology}

\subsection{Scenario/network design}

To investigate the influence of units of information on a DMS on driver speeding behavior, a medium-fidelity driving simulator (Fig. 1) at the Safety and Behavioral Analysis (SABA) Center at Morgan State University was used. A virtual realistic environment on MD-295 was created using the software VR-Design Studio developed by FORUM8 Co. [34]. Data such as acceleration, braking, steering control and speed were recorded in real time by the FORUM8 software.

MD-295, a state highway connecting Washington, D.C., to Baltimore, Maryland, with a posted speed limit of $55 \mathrm{mph}$, was chosen for this study. The study area of $52 \mathrm{mi}^{2}$ extended from MD-100 to beyond I-695 on MD-295. MD-295 past MD-100 starts with two $12-\mathrm{ft}$ lanes and expands to three 12-ft lanes past I-195. The study area and the location of the DMSs are shown in Fig. 2.

Five phases of speeding behavior were tested as the vehicles approached and passed the DMS. The initial speed area and the post DMS areas are arbitrary distances of $328 \mathrm{ft}(100 \mathrm{~m})$, when the participant is at or above the posted speed limit in the initial phase, and the final phase is when the participant has crossed the DMS. The visible area and readable areas are the distances at which the signs become visible and legible as perceived by the participants. The lost legibility distance is when the participant loses visibility of the DMS before they reach the sign. The phase distances can differ depending upon various factors such as road geometry, size of the sign, 
Table 2 Socio-demographic Characteristics of the Participants

\begin{tabular}{|c|c|c|}
\hline Variables & Description & Percentage \\
\hline \multirow[t]{2}{*}{ Gender } & Male & $55 \%$ \\
\hline & Female & $45 \%$ \\
\hline \multirow[t]{5}{*}{ Age } & $18-25$ & $33 \%$ \\
\hline & $26-35$ & $39 \%$ \\
\hline & $36-45$ & $11 \%$ \\
\hline & $46-55$ & $10 \%$ \\
\hline & $>55$ & $7 \%$ \\
\hline \multirow[t]{3}{*}{ Familiarity with Study Area } & Yes & $57 \%$ \\
\hline & Somewhat & $29 \%$ \\
\hline & No & $14 \%$ \\
\hline \multirow[t]{6}{*}{ Education } & High School or less & $14 \%$ \\
\hline & Associate Degree & $15 \%$ \\
\hline & Undergraduate student & $36 \%$ \\
\hline & Undergraduate degree completed & $11 \%$ \\
\hline & Post Graduate student & $15 \%$ \\
\hline & Post Graduate degree completed & $9 \%$ \\
\hline \multirow[t]{4}{*}{ Household Income } & $<\$ 20,000$ & $42 \%$ \\
\hline & $\$ 20,000-\$ 29,999$ & $15 \%$ \\
\hline & $\$ 30,000-\$ 49,999$ & $23 \%$ \\
\hline & $>\$ 50,000$ & $20 \%$ \\
\hline
\end{tabular}

Table 3 Descriptive statistics and ANOVA of different phases by units of information

\begin{tabular}{|c|c|c|c|c|c|c|}
\hline \multicolumn{2}{|c|}{ Information on DMS } & \multirow{2}{*}{$\frac{N}{54}$} & \multirow{2}{*}{$\begin{array}{l}\text { Mean Speed (mph) } \\
39.98\end{array}$} & \multirow{2}{*}{$\begin{array}{l}\text { Std. Deviation } \\
7.88\end{array}$} & \multirow{2}{*}{$\frac{F}{0.301}$} & \multirow{2}{*}{$\frac{\operatorname{Sig}}{0.877}$} \\
\hline $6-7$ units & Initial Speed & & & & & \\
\hline & Visible Area & 54 & 38.9 & 7.76 & & \\
\hline & Readable Area & 54 & 38.51 & 8.25 & & \\
\hline & Lost legibility & 54 & 38.47 & 8.56 & & \\
\hline & Post DMS Area & 54 & 38.94 & 8.31 & & \\
\hline \multirow[t]{5}{*}{5 units } & Initial Speed & 41 & 39.21 & 3.84 & 0.693 & 0.598 \\
\hline & Visible Area & 41 & 38.95 & 2.88 & & \\
\hline & Readable Area & 41 & 38.32 & 3.37 & & \\
\hline & Lost legibility & 41 & 38.08 & 5.14 & & \\
\hline & Post DMS Area & 41 & 38.16 & 3.78 & & \\
\hline \multirow[t]{5}{*}{4 units } & Initial Speed & 77 & 39.14 & 4 & 0.902 & 0.463 \\
\hline & Visible Area & 77 & 38.5 & 3.48 & & \\
\hline & Readable Area & 77 & 38.53 & 4.25 & & \\
\hline & Lost legibility & 77 & 38.88 & 4.86 & & \\
\hline & Post DMS Area & 77 & 39.62 & 4.74 & & \\
\hline \multirow[t]{5}{*}{$2-3$ units } & Initial Speed & 124 & 39.84 & 7.48 & 6.745 & $0.000^{*}$ \\
\hline & Visible Area & 124 & 38.68 & 7.61 & & \\
\hline & Readable Area & 124 & 38.48 & 8.01 & & \\
\hline & Lost legibility & 124 & 43.74 & 8.38 & & \\
\hline & Post DMS Area & 124 & 43.96 & 8.17 & & \\
\hline
\end{tabular}


Table 4 Tukey's Post Hoc Analysis - 2-3 units of information

\begin{tabular}{|c|c|c|c|c|c|}
\hline Information on DMS & Phase & & $\begin{array}{l}\text { Mean Difference } \\
(I-J)\end{array}$ & Std. Error & Sig. \\
\hline \multirow[t]{20}{*}{$2-3$ units } & \multirow[t]{4}{*}{ Initial Speed } & Visible Area & 1.153 & 1.590 & 0.936 \\
\hline & & Readable Area & 1.351 & 1.590 & 0.891 \\
\hline & & Lost legibility & -3.903 & 1.590 & 0.063 \\
\hline & & Post DMS Area & $-4.130^{\mathrm{a}}$ & 1.590 & 0.042 \\
\hline & \multirow[t]{4}{*}{ Visible Area } & Initial Speed & -1.153 & 1.590 & 0.936 \\
\hline & & Readable Area & 0.197 & 1.590 & 1.000 \\
\hline & & Lost legibility & $-5.056^{a}$ & 1.590 & 0.006 \\
\hline & & Post DMS Area & $-5.283^{*}$ & 1.590 & 0.003 \\
\hline & \multirow[t]{4}{*}{ Readable Area } & Initial Speed & -1.351 & 1.590 & 0.891 \\
\hline & & Visible Area & -0.197 & 1.590 & 1.000 \\
\hline & & Lost legibility & $-5.254^{\mathrm{a}}$ & 1.590 & 0.004 \\
\hline & & Post DMS Area & $-5.481^{\mathrm{a}}$ & 1.590 & 0.002 \\
\hline & \multirow[t]{4}{*}{ Lost legibility } & Initial Speed & 3.903 & 1.590 & 0.063 \\
\hline & & Visible Area & $5.056^{\mathrm{a}}$ & 1.590 & 0.006 \\
\hline & & Readable Area & $5.254^{\mathrm{a}}$ & 1.590 & 0.004 \\
\hline & & Post DMS Area & -0.226 & 1.590 & 1.000 \\
\hline & \multirow[t]{4}{*}{ Post DMS Area } & Initial Speed & $4.130^{\mathrm{a}}$ & 1.590 & 0.042 \\
\hline & & Visible Area & $5.283^{\mathrm{a}}$ & 1.590 & 0.003 \\
\hline & & Readable Area & $5.481^{a}$ & 1.590 & 0.002 \\
\hline & & Lost legibility & 0.226 & 1.590 & 1.000 \\
\hline
\end{tabular}

a. The mean difference is significant at the 0.05 level

perception and traffic ahead, among other things. The road geometry remains unchanged throughout MD-295 except when the lanes expand from two to three lanes past I-195 while the sign dimensions are consistent throughout. Although, the Manual on Uniform Traffic Control Devices (MUTCD) was consulted to adhere to the sign visibility guidelines, being a driving simulator, it is not possible to affirm to it, as visibility of the sign would be dependent on what the participant's see on the simulator screens. Hence, the distances used for analysis for the five phases were measured by three independent people as they perceived them, and these distances were averaged and used for all subsequent calculations. The different phases along with the signs used are shown in Fig. 3.

The traffic for this study was set to Level of Service (LOS) $\mathrm{C}$ as defined by the Highway Capacity Manual
(HCM), to mimic commuting hours, albeit without any incidents, at least a mile before DMS placement, and to capture true initial speed before the DMS becomes visible. A total of 65 individuals from different socioeconomic backgrounds participated in the study and drove through 296 simulation sessions over six scenarios. Each of the six scenarios had two DMS messages, displaying a mix of 2-7 units of information. Examples of some units of information used in this study are shown in Table 1.

\section{Survey questionnaires}

Prior to the start of the simulation sessions, a sociodemographic survey was filled out by all participants. Essential information such as age, gender, education level and household income, etc., was recorded through the survey. The survey responses were used to investigate

Table 5 Descriptive statistics and ANOVA of different DMSs by units of information

\begin{tabular}{llllll}
\hline Information on DMS & N & Mean Speed $(\mathrm{mph})$ & Std. Deviation & F & 6.873 \\
\hline $6-7$ units & 270 & 38.96 & 8.11 & \\
5 units & 205 & 38.55 & 3.86 & \\
4 units & 385 & 38.93 & 4.29 & \\
$2-3$ units & 620 & 40.94 & 7.91 & \\
\hline
\end{tabular}

*Statistically significant as $P<0.05$ at $95 \%$ Confidence Interval 
Table 6 Tukey's Post Hoc Analysis - All units of information

\begin{tabular}{|c|c|c|c|c|c|}
\hline \multicolumn{3}{|c|}{ Information on DMS } & \multirow{2}{*}{$\begin{array}{l}\text { Mean Difference }(\mathrm{I}-\mathrm{J}) \\
0.414\end{array}$} & \multirow{2}{*}{$\frac{\text { Std. Error }}{0.816}$} & \multirow{2}{*}{$\frac{\text { Sig. }}{0.957}$} \\
\hline All units & $6-7$ units & 5 units & & & \\
\hline & & 4 units & 0.025 & 0.699 & 1.000 \\
\hline & & $2-3$ units & $-1.980^{\mathrm{a}}$ & 0.642 & 0.011 \\
\hline & 5 units & $6-7$ units & -0.414 & 0.816 & 0.957 \\
\hline & & 4 units & -0.389 & 0.761 & 0.957 \\
\hline & & $2-3$ units & $-2.394^{a}$ & 0.709 & 0.004 \\
\hline & 4 units & $6-7$ units & -0.025 & 0.699 & 1.000 \\
\hline & & 5 units & 0.389 & 0.761 & 0.957 \\
\hline & & $2-3$ units & $-2.005^{\mathrm{a}}$ & 0.571 & 0.003 \\
\hline & $2-3$ units & $6-7$ units & $1.980^{\mathrm{a}}$ & 0.642 & 0.011 \\
\hline & & 5 units & $2.394^{a}$ & 0.709 & 0.004 \\
\hline & & 4 units & $2.005^{\mathrm{a}}$ & 0.571 & 0.003 \\
\hline
\end{tabular}

${ }^{a}$. The mean difference is significant at the 0.05 level

the possibility of a correlation between speeding behavior and participant socio-demographics.

The participants filled out a post simulation survey after driving all six scenario sessions, noting the level and type of discomfort, if any, experienced during the simulation session and their experience using the driving simulator.

\section{Study data}

Institutional Review Board (IRB) approval was received before participants were recruited for the study. Flier were distributed across Morgan State University (MSU), Towson University, Baltimore City and by word of mouth to invite participants for the study. Participants were compensated at the rate of $\$ 15$ per hour for their contribution to the study. They were notified that there would be consequences in the form of penalties for rash driving and getting involved in crashes, to ensure driving realism. Before the start of the simulation session, the participants were given the opportunity to become familiar with the driving simulator. The descriptive statistics of all the participants are shown in Table 2.

\section{Results and discussion}

To identify the changes in average speed across the five phases for DMSs involving all units of information, a single factor ANOVA analysis was carried out. The descriptive statistics and the resulting ANOVA significance are shown in Table 3.

Only DMSs with 2-3 units of information were found to be statistically significant as seen in Table 3. A post hoc analysis (Table 4) revealed that participants increased their speeds as soon as they lost sight of the DMS. This possibly could be attributed to the brief moments during which the participants perceived the message on the sign and then moved on as soon as they comprehended the message.

To determine the optimum number of units of information on a DMS, an ANOVA analysis was carried out comparing average overall speed across the five phases among the DMSs with different units of information. The descriptive statistics and the resulting ANOVA significance are shown in Table 5.

The changes in mean speed across all DMSs were found to be statistically significant as seen in Table 5 . A post hoc analysis (Table 6) revealed that only DMSs with 2-3 units of information had statistically significant differences in mean speed. As mentioned earlier, this could possibly be attributed to the shorter time taken to perceive DMSs with 2-3 units of information compared to others. The difference in mean speed is at least around $2 \mathrm{mph}$ over DMSs with more than 2-3 units of information.

The mean speed trends based on different units of information are shown in Fig. 4. The trends show the significant change in speed displayed by the participants encountering a DMS with 2-3 units of information, especially after passing the readable area.

To identify whether there is any correlation between mean speeds based on units of information on a DMS and sociodemographic characteristics of the participants, an ordinary least squares (OLS) regression was performed. The results of the OLS regression are shown in Table 7.

The constants are high compared to the coefficients which probably means that there are a lot more factors contributing to speed than just the factors considered in the model. When comparing DMSs with all units of information, young participants in the age group of 26-35 tend to speed more especially when DMSs consist of 2-4 units of information. This could possibly be attributed to younger participants perceiving messages faster. When encountering DMSs with 6-7 units of information, participants older than 55 tend to slow down as compared to the younger age group of 18-25. This could possibly mean that they take more time to perceive the amount of information on a DMS consisting of 6-7 units. Participants in the age group of 36-45 start lowering their speeds once they start encountering DMSs with 4 or more units of information. Although male participants slowed down more than female participants while they encountered 4 units of information, gender difference was not a factor of significance when comparing overall units of information. Additional OLS regressions were carried out on sociodemographic characteristics including income and education but were found to be insignificant and not included in the results. 


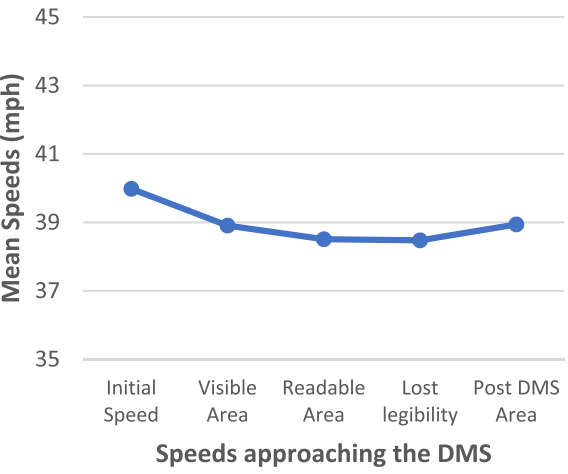

a DMS with 6-7 units of information

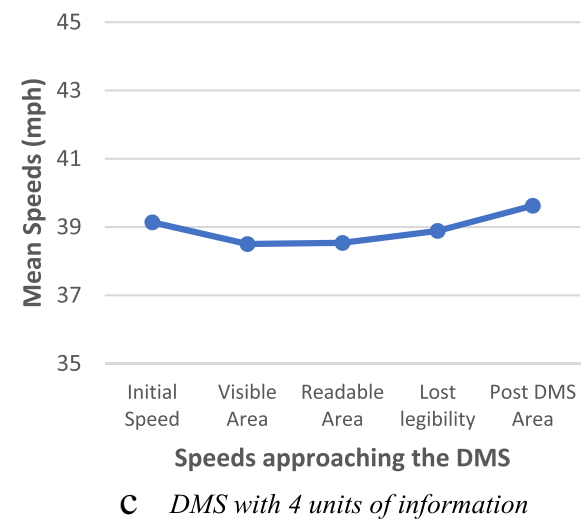

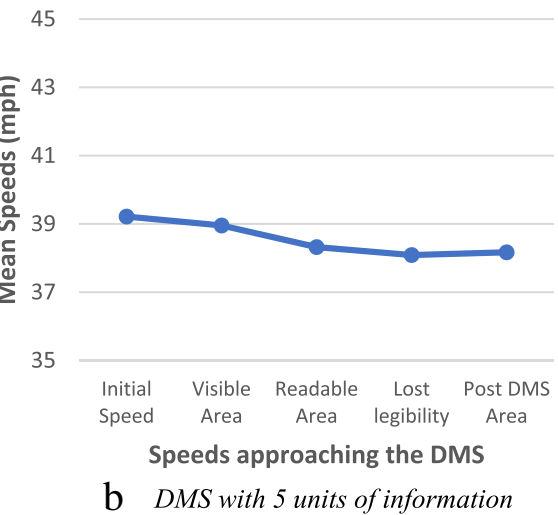

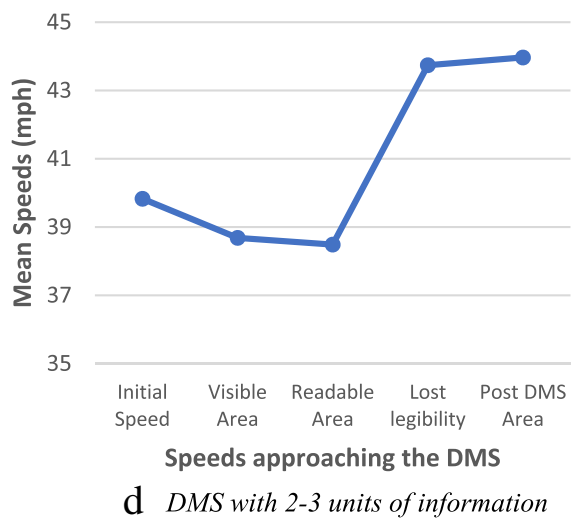

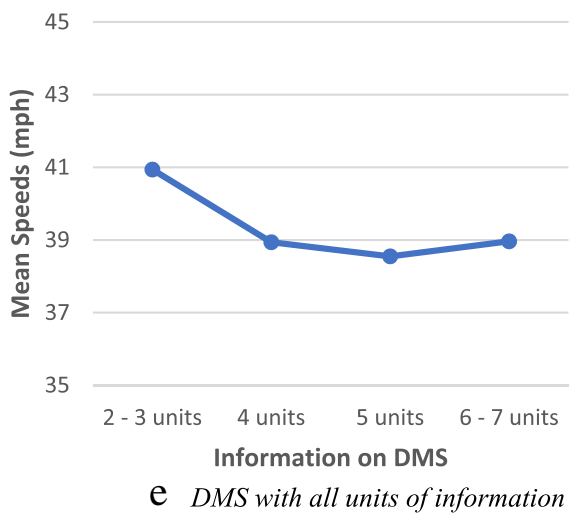

Fig. 4 Mean Speed Trends

\section{Conclusions}

This study investigated the influence of units of information on DMSs on driver speeding behavior, using a medium-fidelity driving simulator. A total of 296 simulation runs were conducted involving 65 participants from different socio-demographic backgrounds. In the post simulation survey, $98 \%$ of the participants agreed that the simulation session felt realistic. ANOVA and post-hoc analysis showed that the DMSs with 2-3 units of information were the most effective to prevent gradual drops in speed while drivers read the signs. Having fewer units of information makes the DMSs easier and faster to perceive and thus can help move traffic faster. This result is consistent with the observations made by Chatterjee et al. [18] which revealed that, the simpler the information displayed on the DMS, the easier it is understood with an increased compliance from drivers. DMSs with more units of information cause drivers to slow down and this could increase congestion, which is consistent with observations from Guattari et al. [27] where complex messages led to greater reduction in speed; and by Jamson et al. [31] in which one or 
Table 7 Ordinary least squares (OLS) regression results

\begin{tabular}{|c|c|c|c|c|}
\hline & Coefficient & Std. Error & t-ratio & $p$-value \\
\hline \multicolumn{5}{|l|}{ All units } \\
\hline const & 37.6030 & 1.75017 & 21.49 & $<0.0001^{*}$ \\
\hline Male & 0.852680 & 0.633566 & 1.346 & 0.1786 \\
\hline 26 to 35 & 4.12656 & 0.850250 & 4.853 & $<0.0001^{*}$ \\
\hline 36 to 45 & -0.178345 & 1.02615 & -0.1738 & 0.8620 \\
\hline 46 to 55 & 0.881788 & 0.975464 & 0.9040 & 0.3662 \\
\hline$>55$ age & -1.03709 & 1.37046 & -0.7567 & 0.4493 \\
\hline \multicolumn{5}{|l|}{$6-7$ units } \\
\hline const & 35.5793 & 4.11774 & 8.640 & $<0.0001^{*}$ \\
\hline Male & 2.09607 & 1.24063 & 1.690 & 0.0924 \\
\hline 26 to 35 & 0.205542 & 1.60506 & 0.1281 & 0.8982 \\
\hline 36 to 45 & -3.16696 & 1.83939 & -1.722 & 0.0864 \\
\hline 46 to 55 & 0.635486 & 1.66670 & 0.3813 & 0.7033 \\
\hline$>55$ age & -5.54713 & 2.10955 & -2.630 & $0.0091^{*}$ \\
\hline \multicolumn{5}{|l|}{5 units } \\
\hline const & 42.0496 & 2.19147 & 19.19 & $<0.0001^{*}$ \\
\hline Male & -1.25050 & 0.782958 & -1.597 & 0.1119 \\
\hline 26 to 35 & 0.313431 & 0.875176 & 0.3581 & 0.7206 \\
\hline 36 to 45 & -0.0151478 & 1.15074 & -0.01316 & 0.9895 \\
\hline 46 to 55 & 0.831526 & 0.966787 & 0.8601 & 0.3908 \\
\hline$>55$ age & 1.98762 & 1.42122 & 1.399 & 0.1636 \\
\hline \multicolumn{5}{|l|}{4 units } \\
\hline const & 37.3436 & 1.25707 & 29.71 & $<0.0001^{*}$ \\
\hline Male & -1.05145 & 0.494319 & -2.127 & $0.0341^{*}$ \\
\hline 26 to 35 & 2.36136 & 0.707826 & 3.336 & $0.0009^{*}$ \\
\hline 36 to 45 & -2.85666 & 0.836796 & -3.414 & $0.0007^{*}$ \\
\hline 46 to 55 & -0.665750 & 0.864182 & -0.7704 & 0.4416 \\
\hline$>55$ age & -0.953455 & 1.13846 & -0.8375 & 0.4029 \\
\hline \multicolumn{5}{|l|}{$2-3$ units } \\
\hline const & 38.3359 & 3.65360 & 10.49 & $<0.0001^{*}$ \\
\hline Male & 1.60923 & 1.30303 & 1.235 & 0.2173 \\
\hline 26 to 35 & 7.05271 & 1.82269 & 3.869 & $0.0001^{*}$ \\
\hline 36 to 45 & 0.796663 & 2.17824 & 0.3657 & 0.7147 \\
\hline 46 to 55 & 2.05524 & 2.09469 & 0.9812 & 0.3269 \\
\hline$>55$ age & -0.764986 & 3.23152 & -0.2367 & 0.8129 \\
\hline
\end{tabular}

*Statistically significant as $P<0.05$ at $95 \%$ Confidence Interval

two-line messages did not interrupt the driving performance contrary to the four-line ones that led to reduction in speed and increased headway. It was seen in this study that having 6-7 units of information on a DMS prompts older drivers to slow down. Thus, having fewer units of information to convey the appropriate message will possibly help older drivers comprehend the messages faster, without a gradual decrease in a speed. Based on the findings of this study, the authors propose that
DMSs with 2-3 units of information should be displayed on high-speed arterials and freeways so that drivers can comprehend them faster without slowing down. DMSs with more than 3 units of information can be used on roads which have heavy traffic or during peak hours when change in speed would not be an issue. Pilot studies should be carried out to evaluate and corroborate the findings of this study. Future studies would involve validating the results of this driving simulator study by comparing it with real world data.

\section{Acknowledgements}

The authors would like to thank the Maryland State Highway Association (SHA) for their funding support throughout the study.

\section{Funding}

The study was funded by the Maryland State Highway Association through grant number MD-18-SP709B4H.

\section{Availability of data and materials}

The datasets used and/or analyzed during the current study are available from the corresponding author on reasonable request.

\section{Authors' contributions}

Study conception and design: SB, MJ, DB; Data collection: SB, DB, NK; Analysis and interpretation of results: SB, MJ; Draft manuscript preparation: SB, NK, MJ. All authors reviewed the results and approved the final version of the manuscript.

\section{Competing interests}

The authors declare that they have no competing interests.

\section{Publisher's Note}

Springer Nature remains neutral with regard to jurisdictional claims in published maps and institutional affiliations.

Received: 13 November 2018 Accepted: 19 February 2019

Published online: 28 February 2019

\section{References}

1. Huayan, S., Haijun, H., \& Ziyou, G. (2008). Design real-time traffic information by cell transmission model. Journal-Beijing University Of Aeronautics And Astronautics, 34(2), 234

2. Yan, X., Li, X., Liu, Y., \& Zhao, J. (2014). Effects of foggy conditions on drivers' speed control behaviors at different risk levels. Safety Science, 68, 275-287.

3. B. R. Ullman, N. D. Trout, and C. L. Dudek, "Use of graphics and symbols on dynamic message signs: technical report," Texas Transportation Institute, The Texas A \& M University System2009.

4. Selby, R. (2016). Impact of dynamic message signs on driver behavior under reduced visibility conditions.

5. Collura, J., \& Fisher, D. (2009). Evaluation of dynamic message sign deployments and their effects on older drivers.

6. Kolisetty, V. G. B., Iryo, T., Asakura, Y., \& Kuroda, K. (2006). Effect of variable message signs on driver speed behavior on a section of expressway under adverse fog conditions-A driving simulator approach. Journal of Advanced Transportation, 40(1), 47-74.

7. Haghani, A., Hamedi, M., Fish, R. L., \& Nouruzi, A. (2013). Evaluation of dynamic message signs and their potential impact on traffic flow.

8. Venkat, B. K. (2014). A driving simulator study to evaluate the impact of portable changeable message signs (PCMS) on driver speed characteristics.

9. Boyle, L. N., \& Mannering, F. (2004). Impact of traveler advisory systems on driving speed: Some new evidence. Transportation Research Part C: Emerging Technologies, 12(1), 57-72.

10. Wang, J.-H., Keceli, M., \& Maier-Speredelozzi, V. (2009). Effect of dynamic message sign messages on traffic slowdowns.

11. Jeihani, M., \& Ardeshiri, A. (2013). Exploring travelers' behavior in response to dynamic message signs (DMS) using a driving simulator. 
12. Dudek, C. L., \& Ullman, G. L. (2004). Dynamic message sign message design and display manual. Texas transportation institute. In Texas A \& M University system.

13. Dudek, C. L., \& Ullman, G. L. (2001). Variable message sign operations manual final report.

14. Dudek, C. (2002). Guidelines for changeable message sign messages. Washington, DC: FHWA, US Department of Transportation.

15. Erke, A., Sagberg, F., \& Hagman, R. (2007). Effects of route guidance variable message signs (VMS) on driver behaviour. Transportation Research Part F: Traffic Psychology and Behaviour, 10(6), 447-457.

16. Cooper, B., \& Sawyer, H. E. (2005). Assessment of M25 automatic fog-warning system-final report.

17. Erke, A., \& Sagberg, F. (2006). Effects of variable message signs (VMS) on driver attention and behaviour. Association for European Transport.

18. Chatterjee, K., \& Mcdonald, M. (2004). Effectiveness of using variable message signs to disseminate dynamic traffic information: Evidence from field trails in European cities. Transport Reviews, 24(5), 559-585.

19. Virginia Department of Transportation, "Changeable Message Sign (CMS) Policy," 2016.

20. Colorado Department of Transportation, "Guidelines on variable message signs (VMS)," 2017.

21. Harder, K. A., Bloomfield, J., \& Chihak, B. J. (2003). The effectiveness and safety of traffic and non-traffic related messages presented on changeable message signs (CMS).

22. Yan, X., \& Wu, J. (2014). Effectiveness of variable message signs on driving behavior based on a driving simulation experiment. Discrete Dynamics in Nature and Society, 2014.

23. Jeihani, M., Banerjee, S., Ahangari, S., \& Brown, D. D. (2018). The Potential Effects of Composition and Structure of Dynamic Message Sign Messages on Driver Behavior using a Driving Simulator (No. MD-18-SHA/MSU/4-14).

24. Jeihani, M., \& Banerjee, S. (2018). Drivers' behavior analysis under reduced visibility conditions using a driving simulator. Journal of Traffic and Logistics Engineering, 6(2), 48-52. https://doi.org/10.18178/jtle.6.2.48-52.

25. Banerjee, S., Jeihani, M., \& Moghaddam, R. Z. (2018). Impact of Mobile work zone barriers on driving behavior on arterial roads. Journal of Traffic and Logistics Engineering, 6(2), 37-42. https://doi.org/10.18178/jtle.6.2.37-42.

26. Jeihani, M., NarooieNezhad, S., \& Kelarestaghi, K. B. (2017). Integration of a driving simulator and a traffic simulator case study: Exploring drivers' behavior in response to variable message signs. IATSS Research, 41(4), 164-171.

27. Guattari, C., De Blasiis, M. R., \& Calvi, A. (2012). The effectiveness of variable message signs information: A driving simulation study. Procedia-Social and Behavioral Sciences, 53, 692-702.

28. Dutta, A., Fisher, D. L., \& Noyce, D. A. (2004). Use of a driving simulator to evaluate and optimize factors affecting understandability of variable message signs. Transportation Research Part F: Traffic Psychology and Behaviour, 7(4-5), 209-227.

29. Oregon Department of Transportation, "Guidelines for the Operation of Variable Message Signs on State Highways," 2008.

30. Hogema, J., \& Van Der Horst, R. (1997). Evaluation of A16 motorway fogsignaling system with respect to driving behavior. Transportation Research Record: Journal of the Transportation Research Board, 1573, 63-67.

31. Jamson, S. L., Tate, F., \& Jamson, A. H. (2005). Evaluating the effects of bilingual traffic signs on driver performance and safety. Ergonomics, 48(15), 1734-1748.

32. Emmerink, R. H., Nijkamp, P., Rietveld, P., \& Van Ommeren, J. N. (1996). Variable message signs and radio traffic information: An integrated empirical analysis of drivers' route choice behaviour. Transportation Research Part A: Policy and Practice, 30(2), 135-153.

33. Rämä, P., \& Kulmala, R. (2000). Effects of variable message signs for slippery road conditions on driving speed and headways. Transportation research part F: traffic psychology and behaviour, 3(2), 85-94.

34. FORUM8. 3D VR \& Visual Interactive Simulation. Available: http://www. forum8.com/. Accessed 22 Oct 2018. 